\title{
Educación artística más allá del coronavirus: diálogo con Estitxu Aberasturi, Carlos Escaño y Carmen María Belmonte
}

Ricard HUERTA. Universitat de València (España). ricard.huerta@uv.es

Esta entrevista a tres bandas supone una apuesta de la publicación EARI Educación Artística Revista de Investigación por indagar en los aires de renovación que estamos viviendo, acercándonos a las opiniones de tres docentes con una dilatada experiencia, tres profesionales de la educación artística que proceden de realidades periféricas: Andalucía, Euskadi y País Valenciano. Se trata de una profesora de la UPV-EHU, un profesor de la Universidad de Sevilla, y una profesora del Instituto de Educación Secundaria Lluís Vives de València. Son tres figuras que consideramos importantes, con trayectorias consolidadas, que destacan por su implicación en temas de índole social, apostando por la acción participativa y por la denuncia de determinadas situaciones injustas. La entrevista se llevó a cabo en julio de 2020, un momento delicado para la educación artística en España, debido a la intención del Ministerio de sacar adelante una nueva Ley de Educación LOMLOE, que de salir adelante tal y como está redactada en su documento base, castigaría la presencia de la educación de las artes al nefasto limbo de la "opcionalidad". En caso de aprobarse esta ley, las artes visuales y el estudio de las imágenes quedarían como un residuo educativo, arrinconando así el conocimiento de lo visual a un grado ínfimo de presencia curricular. Esto supondría, evidentemente, la desaparición de necesidades docentes, una rebaja efectiva de profesionales en las aulas, y por ende, una casi desaparición de la educación artística de la realidad escolar. Ante tal posibilidad, se han desarrollado acciones reivindicativas en distintos ámbitos, habiéndose presentado un pliego de enmiendas a la Ley, y destacando una serie de iniciativas en redes sociales que están produciendo un avance positivo entre los distintos colectivos profesionales (profesorado de secundaria y universidad, especialmente), al que se han unido profesionales de las artes (artistas, directores de cine, responsables de cultura y educación), en una campaña de visibilidad del sector que está teniendo una cierta repercusión. En la entrevista se cruzan las opiniones de tres profesionales muy implicados en la realidad de la educación en artes, por lo que esta conversación nos ofrece una oportunidad para escuchar tres voces relevantes 
en el panorama de la reflexión sobre el marco en el que se están desarrollando los distintos ámbitos y tendencias de la enseñanza de las artes.

\section{Ricard Huerta: ¿Cómo se vive la educación artística a nivel profesional en estas circunstancias de crisis (sanitaria, curricular, laboral, económica)?}

Estitxu Aberasturi: La educación artística, a pesar de su carácter práctico y de taller, creo que se ha adaptado razonablemente bien a las circunstancias. El profesorado, acostumbrado a trabajar acompañando los procesos creativos, ha adecuado sus propuestas a los recursos domésticos, y los encuentros con los grupos en tutorías on-line han sido intensos y productivos. En este sentido, el acompañamiento al estudiante ha estado más personalizado y nos ha dado la posibilidad de llegar a más personas. A pesar de ello, hemos perdido el encuentro e intercambio entre los grupos. No contar con lo presencial ha provocado que se perdiese una parte importante del proceso de aprendizaje, ya que el encuentro en el taller permite observar y compartir el trabajo de los Otros, trabajar en compañía pudiendo comentar o formular preguntas y dudas, escuchar, buscar estrategias expositivas grupales, que no se han podido dar. Esta situación de crisis sanitaria se vive con preocupación. No concibo una educación mediada únicamente por la tecnología, con la ratio de estudiantes tan alto que tenemos, de cien personas por grupo en nuestra universidad. La relación entre las personas y los grupos mediada por la tecnología hace inviable una formación relevante y con sentido.

Carmen María: En esta crisis sanitaria la educación artística ha demostrado lo importante que es para mantener la mente activa, para buscar nuevos recursos expresivos, nuevas formas de manifestarse, de contar y de entender a través de todo tipo de imágenes. El profesorado de artes de secundaria hemos tenido que buscar formas de transmitir a nuestro alumnado pasión por las imágenes, desde la distancia, reinventándonos y superándonos. Hemos buscado temáticas motivadoras para que el alumnado se expresase libremente desde el confinamiento en sus casas, con retos como los famosos challenges recreando obras famosas, que aunque llevábamos años haciéndolo, las redes sociales han divulgado profusamente, como el \#tussenkunsteinquarantaine o \#thegettychallenge. De este modo les hemos acercado a las imágenes de la historia del arte, promoviendo que investigaran sobre ellas. También han contado historias a través de las imágenes generadas \#Desdemiventana \#CCCCHabitantEspais, o han hecho prácticas de \#Urbansketch imaginando otros paisajes posibles fuera de sus casas, o audiovisuales sobre el confinamiento. Nos hemos reinventado usando cualquier recurso a nuestro alcance para seguir educando en el arte y con el arte, tratando de hacer trabajos terapéuticos que ayudasen a expresar lo difícil del momento. Vamos a tener que seguir reinventándonos, lo cual es una buena lección para nuestro alumnado, ya que demostramos que la multiplicidad de respuestas que se pueden generar artísticamente ayuda a resolver conflictos, dado que el pensamiento creativo es flexible y abierto. 
Carlos Escaño: Existe bastante inquietud. Las circunstancias vividas y que estamos viviendo nos obligan a no parcelar su experiencia, de modo que no podemos afrontar el análisis desde una disciplina particular. Todas las denominadas disciplinas académicas van dentro del mismo vagón en este viaje. Y todas las señales indican que se avecina un tiempo en el que si no potenciamos las relaciones solidarias en los diferentes contextos, sean de la índole que sean, educativos, sanitarios, económicos..., y no las anteponemos a la acción competitiva, el resultado será desastroso. Si algo hemos aprendido como sociedad —o deberíamos de haberlo hecho- en los meses más desconcertantes de la pandemia, es una obviedad que parecía imposible en según qué territorios y contextos: la extrema debilidad de nuestra naturaleza física independientemente de los cercamientos fronterizos y clasificaciones étnicas, de clase o de género. Cuando hemos visto cómo un virus ha puesto en jaque a la sociedad globalizada, es inevitable repensar sus bases políticas. Han sido y son días de reflexión sobre las necesidades esenciales de esa sociedad globalizante basada en la omnipresente ley neoliberal del laissez faire. En estos días se ha puesto de relieve la necesidad de la cooperación y solidaridad por encima de los patrones de competencia individual. Los servicios de salud pública se han visibilizado más que nunca como la salvaguarda de nuestra sociedad. Se ha percibido de manera meridiana la necesidad de la ayuda comunitaria como un bien absolutamente necesario, que genera fortaleza de grupo y, por extensión, como individuos: es la única manera de paliar esa extrema debilidad que señalaba. Es un momento crucial para evidenciar la necesidad de la solidaridad, comunidad y cooperación a nivel económico, laboral, educativo y, lógicamente, educativo artístico.

\section{Ricard Huerta: ¿De qué modo podríamos repensar la educación artística en el momento actual?}

Carmen María: Si pensamos a corto plazo, para el curso escolar que empieza en septiembre, tenemos que seguir reinventándonos, cambiando la forma de dar las clases y el tipo de actividades que vamos a poder realizar. Vamos a tener que trabajar el doble con la mitad de recursos. Las administraciones públicas, como siempre dejan el peso de la solución en nuestras manos. Un grupo de 30 o 35 alumnos se va a dividir en dos subgrupos, a los que impartiremos clase en días alternos, de modo que en una semana daremos la mitad de temario. Los contenidos a trabajar no pueden ser los mismos. Hay que pensar cómo trabajar poniendo tareas sugerentes para casa, de forma que el alumnado no se quede descolgado de las materias. Creo que la mejor manera será trabajar por proyectos creativos, planteando al inicio de curso unos objetivos claros, sabiendo qué queremos desarrollar en cada evaluación, que lo podamos resolver tanto presencialmente como online. Tener temáticas claras, como abordar la diversidad, el género, los derechos humanos, el cambio climático, y que los contenidos curriculares giren alrededor de temas transversales, a través de diferentes lenguajes creativos, usando la fotografía, la animación stopmotion, el audiovisual, la performance, la escultura, la pintura. Estas son nuestras herramientas, que han de servir para construir algo. 
Estitxu Aberasturi: Considero que por un lado podríamos reflexionar e investigar sobre el conocimiento que desde las artes se produce, y por otro desvelar las oportunidades que nos dan las artes para lograr un aprendizaje que nos afecte, que nos atreviese y que realmente sea relevante para el estudiante.

Carlos Escaño: En este contexto, la cultura y las artes se hallan en la misma tesitura que cualquier disciplina, aunque no podemos olvidar que nuestra tradición nos interpela, ya que estamos ante el permanente dilema de adaptarse o transformar el contexto. Este es el eje donde nos situamos a la hora de repensar el modelo educativo artístico en la actualidad. Es decir, seguir el modelo darwinista social de adaptación al contexto, donde esa consigna laissez faire se hermana con la ley del más fuerte; o por el contrario, desarrollar el pensamiento brechtiano que sitúa al arte no como un espejo en el que reflejarnos como realidad, sino como un martillo para darle forma. $\mathrm{El}$ arte en nuestra situación pandémica y en el futuro, cercano o no, debe asumir el rol de vanguardia transformadora, como tantas otras veces lo fue. Los educadores y educadoras de las artes, ahora igual que antes, tenemos la tarea de repensarnos y de posicionarnos en la educación como herramienta de cambio social.

\section{Ricard Huerta: ¿Qué aspectos y temáticas se deberían abordar en educación artística?}

Estitxu Aberasturi: Desde las artes visuales abordaría tres aspectos: a) la expresión/ comunicación gráfica, el dibujo; b) la cultura visual, desarrollar un pensamiento/ producción crítica frente a la cultura visual; y c) el arte (contemporáneo) como proceso de investigación/indagación, reflexión social, crítica, diversidad de técnicas y materiales, visita a museos o galerías. En relación a las temáticas, considero que trabajar a través del arte contemporáneo supone abordar muchas de las cuestiones actuales. Los artistas producen sus obras desde una posición situada y global. Trabajar a partir de sus piezas significa investigar sobre los diferentes temas, leer, conocer, contrastar, escuchar, etc. Se trata de compartir el viaje, de descubrir a los artistas contemporáneos con los estudiantes. El trabajo por proyectos podría ser una de las maneras, aunque me interesan más los procesos de investigación-creación artística.

Carmen María: La educación artística trabaja un lenguaje, el de las imágenes, pero como todo lenguaje debe de comunicar, y debe hacerlo bien. Manejamos una sintaxis visual y unos recursos expresivos, acercando al alumnado a la comprensión de los códigos visuales, tanto para entenderlos como para generarlos. En la sociedad actual hay una sobresaturación de imágenes de todo tipo, hemos de trabajar con los filtros adecuados, mostrar al alumnado a ser crítico con ellas, a entenderlas y valorarlas así como a producirlas con criterio. Creo importante poner retos al alumnado en cuanto a qué comunicar y expresar, usar la historia del arte como referente, como hace la publicidad. Cuando el alumnado conoce los referentes en los que se ha inspirado un anuncio de televisión o un videoclip de músicos conocidos comienza a apreciar 
y a valorar el poder de las imágenes. Pero no sólo son importantes los referentes, también la capacidad crítica que tiene el arte como forma expresiva para temas sociales que nos afectan a todos. Apreciar las manifestaciones artísticas, usando el poder de los lenguajes visuales para tener voz social, es la forma de educar en el arte.

Carlos Escaño: Esta pregunta tiene demasiadas respuestas. Del abanico de posibilidades señalaré algunas cuestiones transversales que considero necesario abordar y que podrían atravesar todas esas temáticas probables. La educación artística debe tener una perspectiva emancipadora, inclusiva, crítica, feminista y postdigital. El modo para implementar esta transversalidad depende de muchas circunstancias y aprendizajes metodológicos, pero sobre todo depende de la cuestión esencial de asunción de nuestro trabajo como un ejercicio político que no puede ser neutral.

\section{Ricard Huerta: ¿Cómo podemos incorporar las tecnologías digitales a nuestro trabajo docente?}

Carmen María: Han de ser útiles de trabajo, que no nos dominen. En teoría nuestro alumnado son nativos digitales, pero en la práctica a muchos les cuesta trabajar online. Es curioso que aspirantes a influencer o a youtuber no sepan subir un archivo en pdf al aula virtual. El profesorado de mediana edad ha sabido adaptarse a los retos digitales, en cambio el alumnado que prácticamente ha venido al mundo con un smartphone bajo el brazo encuentra algunas dificultades en el uso educativo de las herramientas digitales. Hemos de usar la tecnología digital y enseñarles a usarla con propiedad. Hay alumnado que no sabe crear una ppt o editar un vídeo sencillo. Los tableros cooperativos como los de Pinterest; las aplicaciones que permiten crear blogs sencillos para realizar trabajos comunes, como Padlet, o cualquier otra aplicación que nos permita subir y compartir información, imágenes, vídeos, la gamificación con juegos creados por nosotros, son recursos interesantes.

Carlos Escaño: Aunque parezca una perogrullada, la clave está en la formación. Digo que parece, pero no lo es a la vista de los acontecimientos. Estamos en un tiempo en el que han empezado a emerger por doquier supuestos expertos de la docencia digital, pero sin haber invertido ni un minuto de formación dentro de los estudios de educación digital. Me ha sorprendido ver a algunos docentes sentenciando, criticando y/o aconsejando sobre educación digital, posicionándose tajantemente, pontificando como si se hubieran doctorado por el mismísimo MIT, pero en realidad su formación en la dimensión digital ha sido casi nula o nula sin el casi. Sencillamente sorprendente. A nadie se le ocurriría hacer lo mismo con disciplinas como la ingeniería industrial, la biología celular, la química orgánica o el derecho administrativo, pero sin embargo con la educación digital sucede. Sucede con la educación digital y con la educación artística, por supuesto. La formación es la clave. Formación crítica, creativa y alejada de patrones utilitaristas e instrumentales. 
Estitxu Aberasturi: A mi modo de ver, ya forman parte de nuestro trabajo docente como una herramienta y un recurso más. En el aula-taller de nuestra facultad contamos con ordenadores y un escáner impresora, para poder realizar búsquedas, editar en vídeo o maquetar un cartel. Muchos artistas incorporan y hacen uso de las tecnologías en sus obras. Sin embargo me gustaría comentar que el reto de nuestra área frente a las tecnologías digitales más que incorporarlas sería ofrecer una formación crítica frente a la cultura visual. Los avances tecnológicos han hecho que la presencia de las imágenes recobre fuerza y estas nos afecten y configuren. Incluso la comunicación, en algunos casos, está mediada por las imágenes. Desarrollar un pensamiento visual crítico resulta necesario y considero que integrar las TIC en la docencia significa incorporar propuestas de uso reflexivo y crítico.

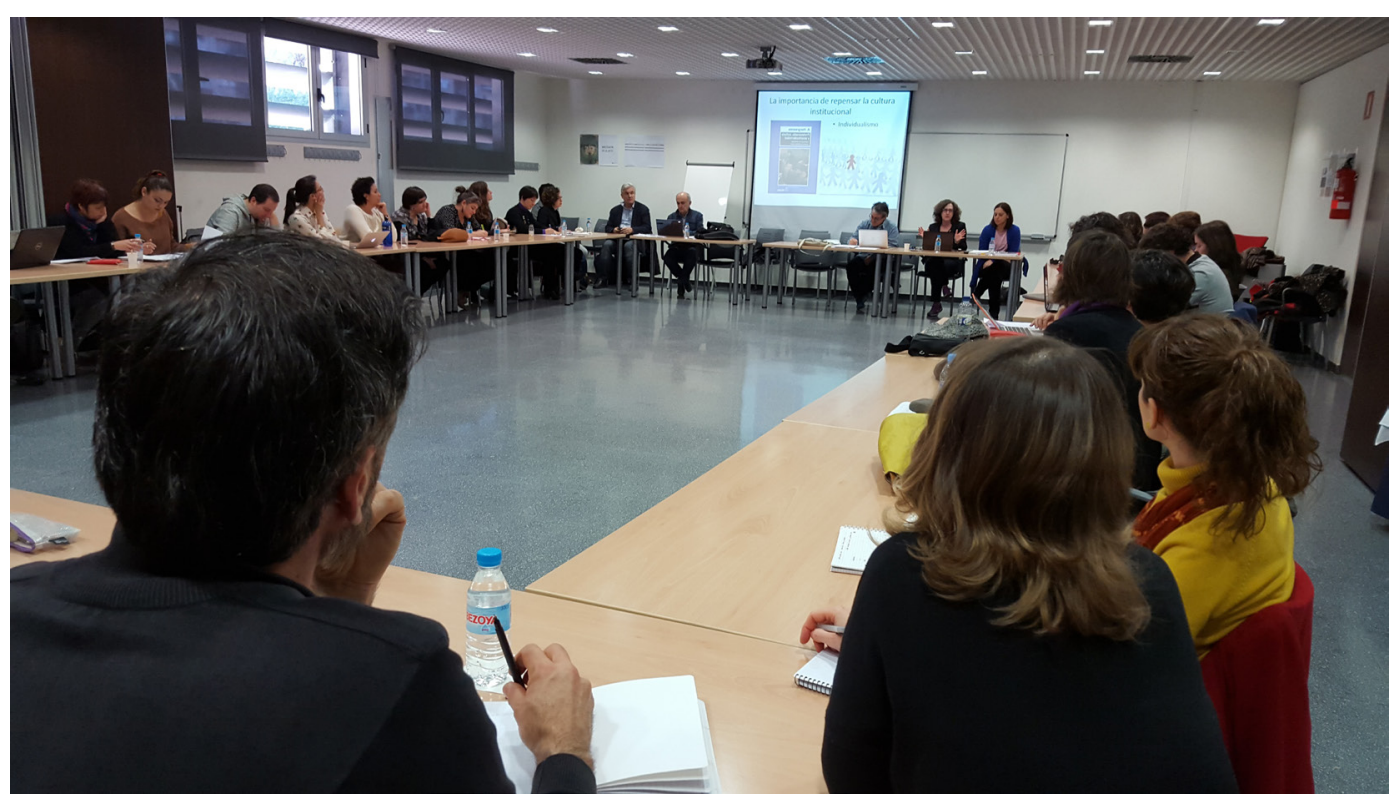

Figura 1. Estitxu Aberasturi, junto a Juana María Sancho y José Miguel Correa en las "Jornadas sobre la Relación Pedagógica" celebradas en València.

\section{Ricard Huerta: ¿Cómo imaginas la educación artística planteada con docencia no presencial o virtual?}

Carmen María: Lo que hemos vivido en el confinamiento ha sido un anticipo de lo que será el próximo curso. Necesitamos aulas virtuales bien surtidas de recursos para poder impartir las clases, para recoger el feedback del alumnado, manejar las videoconferencias correctamente y acostumbrar al alumnado a considerarlas debidamente, y usar aplicaciones a nuestro alcance solo para evaluar de un modo diferente.

Estitxu Aberasturi: En caso de tener que limitarme únicamente a lo virtual, imagino una docencia del "como si", es decir, una docencia que hace como si aprendiésemos, pero no lo hiciésemos en realidad. Para que la propuesta virtual sea realmente de calidad, necesitamos de tiempo para preparar nuevos materiales que se adecúen a las circunstancias. Esto requiere de recursos para generar materiales 
efectivos. Aunque a pesar de ello, no renunciaría a la presencialidad, ya que la considero parte fundamental del aprendizaje. Una docencia únicamente virtual pienso que es parcial y no íntegra. Es posible que los recursos virtuales puedan ofrecernos la posibilidad de diseñar una nueva enseñanza, en todo caso híbrida, mejor pensada, y más ajustada a las necesidades de cada grupo. Esto requiere una inversión en personas y grupos que dediquen su tiempo a pensar y diseñar otras maneras de acercarnos al conocimiento, y no tanto en infraestructuras que muchas veces entorpecen el desarrollo de las personas.

Carlos Escaño: Desde mi modesto punto de vista la formación crítica en el ámbito tecnológico es análoga a la formación crítica en cualquier ámbito, porque el foco de la educación digital no es lo digital, sino lo educativo. La educación digital no es un complemento de la denominada educación presencial. Tiene más que ver con comprender que la educación está inmersa en la sociedad red. El contexto digital nos condiciona como sujetos en relación. Si comprendemos lo digital y su educación como un mero complemento, es entender su naturaleza como algo externo y tratarla al margen de la dimensión educativa para ubicarla en el terreno de lo meramente instrumental. La educación digital y la educación artística necesitan del carácter crítico, emocional, colaborativo y creativo, porque ambas son, precisamente, educación, y la educación debe ser crítica, emocional, colaborativa y creativa. Insisto, el foco en la educación digital es la educación, no lo digital. La educación artística planteada dentro de los tiempos y espacios digitales debe asumir el mismo papel que tiene fuera de estos tiempos y espacios, porque hoy esos dentro y fuera no existen como tal, como compartimentos estancos separados, están simbióticamente hermanados en la sociedad red, porque todo está atravesado por la esfera digital, un espacio simbiótico denominado postdigital.

\section{Ricard Huerta: ¿En qué medida resulta necesario incorporar los audiovisuales a las tareas de la educación artística?}

Estitxu Aberasturi: Personalmente lo considero bastante necesario, porque a través del audiovisual podemos trabajar la imagen y el sonido simultáneamente, además de poder educar en el desarrollo de bastantes capacidades como la escritura (guión), edición (selección), grabación (espacio, observación) dirección (trabajo colaborativo), proyección (exposición, comunicación y debate-foro), etc. Este curso realizamos un proyecto basado en el cine; un estudiante me escribía este mensaje al finalizar el confinamiento: "He escuchado nueva música, he visto más series y cine que nunca y no paramos de consumir las creaciones que ha hecho mucha gente durante el confinamiento. Es impresionante la creatividad y critica o provocación que hay detrás de cada propuesta. (...) Ha sido un cierre muy bueno para la asignatura porque aun estando confinados he sido consciente al parar, de que hemos hecho un montón de vídeos y los hemos compartido; he tenido la oportunidad de constatar todo el valor de lo que nos habias hablado en clase." (Jon). Es fundamental que la educación artística pueda ofrecer una educación 
creativa y crítica frente al audiovisual. No es suficiente con tener una herramienta, hablamos de detenernos en las ideas y los conceptos con los que trabajamos.

Carmen María: Tanto el visionado de audiovisuales como la producción de estos curricularmente están reconocidos en la Educación Plástica, Visual y Audiovisual en todos los cursos de la ESO, al menos en la Comunidad Valenciana, por tanto el profesorado ha de estar bien formado para incorporarlos a su práctica docente. En un mundo dominado por el audiovisual los adolescentes no pueden ser analfabetos audiovisuales, y el profesorado de artes estamos capacitados por nuestra formación para ayudarles a realizar vídeos con un criterio estético y argumental potente. También a enseñarles a ser consumidores de vídeo exigentes y a no aceptar cualquier producto audiovisual como bueno. Una lucha por la calidad en la forma y en el contenido.

Carlos Escaño: Sin el estudio de fundamentos teóricos y prácticos del audiovisual no se puede comprender y transformar la realidad actual, una realidad que está mediatizada y es igualmente mediática. Es así de sencillo y de difícil. Su necesidad de estudio es imperativo social y cultural.

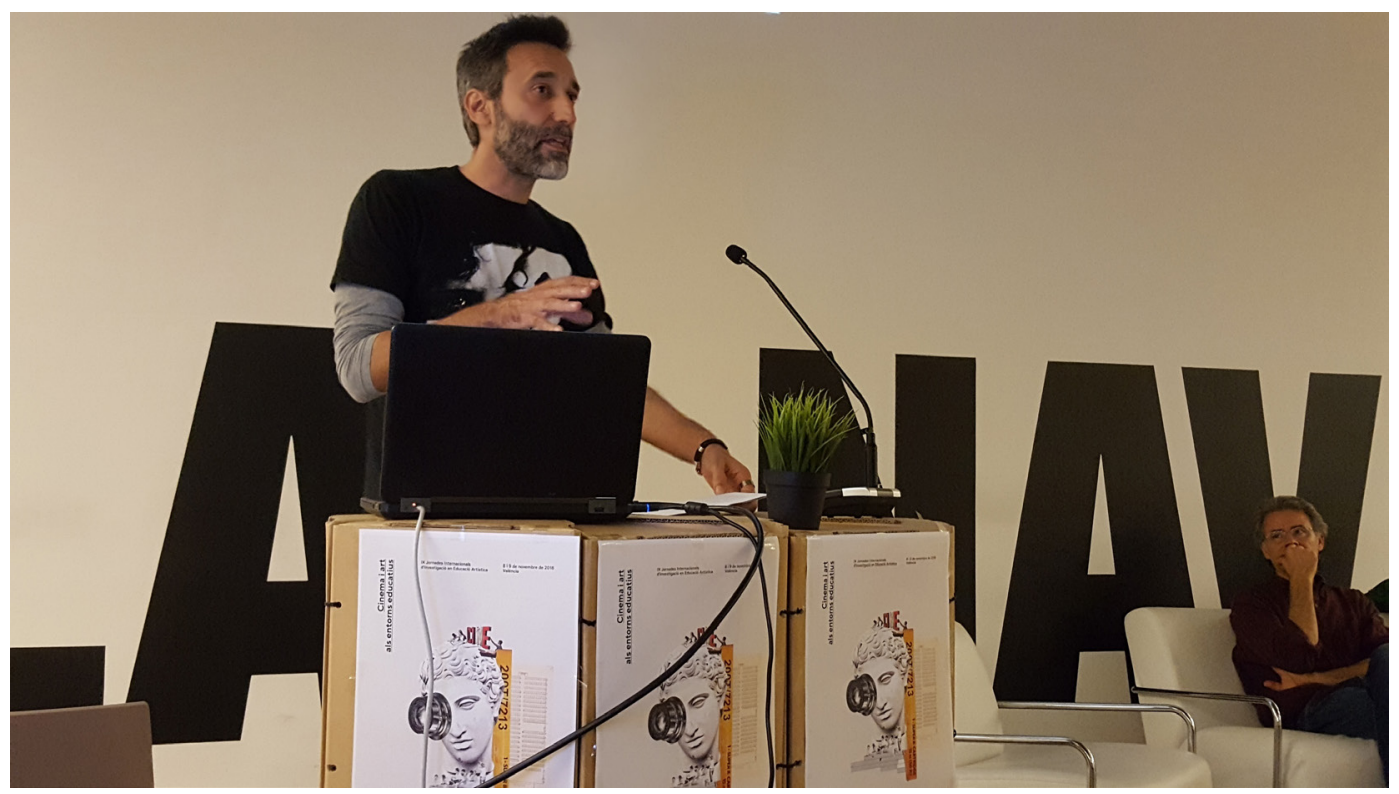

Figura 2. Carlos Escaño durante su intervención en las Jornadas "Cine y arte en los entornos educativos" celebradas en València.

\section{Ricard Huerta: ¿Qué referentes (autores y autoras, trabajos, revistas) deberíamos tener en cuenta en nuestras tareas curriculares?}

Carlos Escaño: Procurando ser coherente con las respuestas anteriores, me centraré en aspectos que tienen que ver con la formación en un enfoque pedagógico más que en cuestiones instrumentales. En este caso, como punto de origen y retorno, el pensamiento pedagógico crítico es la referencia clave. Autores como Paulo Freire, Peter McLaren o Henry Giroux son referencias que marcan tendencia filosófica, 
pedagógica y actitudinal. En una estela del desarrollo crítico de la educación y las artes, no puedo dejar de citar a Ana Mae Barbosa o Dipti Desai. Y también abordando los aspectos educomunicativos aparecen los trabajos de Roberto Aparici y Sara Osuna. Finalmente, en una perspectiva crítica de cultura digital, destacaría a nuestra colega Remedios Zafra y al compañero Petar Jandrić y el grupo que permanece detrás de Postdigital Science and Education.

Estitxu Aberasturi: Plataformas como INSEA (https://www.insea.org) y su revista IJETA (https://www.intellectbooks.com/international-journal-of-educationthrough-art) son referentes internacionales básicos. En el panorama nacional la revista $E A R I$ es un referente, ya que se abordan investigaciones y experiencias concretas que ayudan a acercarse al trabajo que se hace en el área. Arte, individuo $y$ sociedad es otra de las revistas en la que podemos encontrar experiencias e investigación. Monográficos concretos como "El arte nos hace humanas" de Cuadernos de Pedagogía $\left(\mathrm{n}^{\circ} 484,2017\right)$ nos ofrecen una variedad de textos valiosos para la intervenciones curriculares. Algún texto concreto de la revista Invisibilidades también formaría parte de las lecturas recomendadas. Me gusta buscar entre los referentes del área. Me interesa mucho la colección "Posibilidades de ser a través del arte" coordinada por Marian López Fernández-Cao. Además, trato de introducir materiales basados en las artes, como puede ser las referencias a libros de artista, o novela gráfica como por ejemplo Enseñar arte, un desafío, de R. Branham, o algún libro de Keri Smith.

Carmen María: Es importante que el profesorado de artes de secundaria y bachillerato tenga inquietudes e intente estar al día de lo que se cuece en las universidades. Nosotros no nos dedicamos a la investigación como el profesorado universitario, pero hemos de leer y compartir de otros colegas profesores, tanto de secundaria, como de universidad, como de teóricos del arte. Mis referentes los encuentro en Howard Gardner, John Berger, Will Gompertz, Ernst Fischer, Wendy Ann Greenhalgh, María Acaso, Carlos Escaño, algunos manuales sobre TIC como Artefactos digitales, de Conecta 13 (Graó), Dale la vuelta a tu clase, de Jonathan Bergman y Aaron Sams. Libros que me han impresionado últimamente: Diseñador/Ciudadano de Milton Glaser, Pensar con imágenes de Enric Jardí, La cámara de Pandora de Joan Fontcuberta, o Una mappa delle arti nell'epoca digitale de Renato Barilli.

\section{Ricard Huerta: ¿Qué aspectos problemáticos del panorama actual merece la pena valorar en la formación artística de docentes?}

Carmen María: Si los docentes no son de materias artísticas, como el profesorado de inglés que en Primaria imparte la clase de Plástica, al menos hay que enseñarle a apreciar el hecho artístico. A secundaria nos llega alumnado analfabeto visual, ya que la educación artística en primaria se ha limitado a una acción de buena voluntad del profesorado de idiomas. A veces su actuación se ha limitado a dejar 10 minutos de la última hora de clase a hacer un dibujo libre. Ese concepto de dibujo libre 
es muy antiguo, es muy inútil, de relleno. Esto no lo hace todo el profesorado, y muchos se forman con cursos para impartir la educación plástica con cierto nivel de exigencia. Tenemos mucho camino por delante para acabar con ese analfabetismo visual, y aun será peor si en secundaria la nueva ley de educación nos retira a la optatividad.

Carlos Escaño: Algo básico que está por encima de la comprensión y aprendizaje de la dimensión digital: la necesaria desbancarización de la educación. Es algo asombroso que el enfoque de la Escuela Nueva, con las voces de Dewey o Freinet entre tantos, y más de un siglo después, siga siendo nuevo. Ha pasado un siglo largo de educación institucional y en nuestras diferentes realidades plurales e internacionales siguen estando vinculadas esencialmente a la reproducción y transmisividad informativa, algo que en nuestra área se traduce en mecanización, manualización irreflexiva, mero pasatiempo y reproducción de modelos estéticos formales. Todo ello tiene que ver con un modelo bancario de la educación, en este caso, artística. En un momento crítico como el actual es más urgente que nunca desbancarizar nuestro espacio educativo y apostar por una formación docente que se oriente de manera clara por la emancipación social e individual.

Estitxu Aberasturi: Uno de los aspectos problemáticos es la fragmentación disciplinar y las categorías que de ella derivan (los horarios académicos son un reflejo de ello). Todo ello agravado y reflejado en unas leyes educativas que no favorecen ni apoyan una educación que considere la formación artística como una riqueza esencial para una formación integral de la persona. El 30 de junio del 2020, la plataforma INSEA dirigió una carta al gobierno griego advirtiendo que "lamentamos cualquier reducción de la prestación de educación y formación artística a cualquier nivel, ya sea en escuelas, universidades, museos o 'tercer sector' informal, contextos comunitarios". En España hemos creado una plataforma a favor de una Educación No sin Artes (https://educacionnosinartes.wordpress.com/) tratando de recuperar la presencia de las artes en la educación, ahora que se elabora la nueva ley educativa LOMLOE. Me pregunto, ¿Quién tiene algo que perder si se apuesta por una educación con artes? Existen experiencias, propuestas, investigaciones que avalan lo que defendemos. Que no se conozcan ni se hable sobre ellas tiene que ver con una decisión tomada, no con casualidades.

\section{Ricard Huerta: ¿Qué países y tendencias consideráis que están apostando de forma innovadora por medidas para mejorar el arte y la educación?}

Carmen María: Por proyectos europeos realizados en mi centro, he tenido contacto con varios países europeos, y me quedo con Italia, donde a la educación artística se le da más importancia que aquí. Incluso el bachillerato artístico está mejor diseñado allí, tiene más cuerpo, es más contundente que el español, que se queda en una débil sombra del italiano. En el nivel equivalente a la secundaria ya tienen materias artísticas importantes, y llegan al bachillerato con un nivel muy digno. Aquí las 
sucesivas leyes educativas van diluyendo el contorno firme y sólido que tuvo el bachillerato artístico en su día, empeorado por la desaparición de asignaturas artísticas de las pruebas de acceso a la universidad. Estas materias son ahora optativas a las que puede optar incluso alumnado que no es del bachillerato artístico. También encontramos alumnado del artístico que ya no cursa el Dibujo Técnico en $1^{\circ}$ de bachillerato por ser optativo, pero elige Diseño en $2^{\circ}$ de bachillerato sin saber hacer las vistas acotadas y normalizadas de un objeto que diseña o analiza. O sí que lo ha cursado pero el centro educativo no le permite cursar Dibujo Técnico en $2^{\circ}$ porque como la universidad no deja examinarse de esta materia en EVAu al alumnado del artístico, no merece la pena ofertar la asignatura. Un desvarío cuyo único objetivo parece ser seguir diluyendo la fuerza de las artes, hasta hacerlas desaparecer.

Estitxu Aberasturi: Desconozco si hay algún país que haya apostado por medidas para mejorar el arte, únicamente conozco tendencias diversas, que son las que me interesan. Como nos recuerda Aida Sánchez de Serdio al hablarnos del papel social del arte: "Las prácticas artísticas muestran una diversidad indomesticable, y está bien que sea así." Participo en las conferencias sobre ABR (Art Based Research) donde he tenido la oportunidad de conocer el trabajo de la Universidad de Lapland (Finlandia). Allí trabajan con acciones concretas vinculando arte y ecología, promoviendo diálogos a través de las artes (Art Based Action Research). Me interesa la propuesta Room 13 (http://room13international.org) centrada en residencia de artistas en escuelas, con una deriva en centros escolares catalanes. El proyecto promovido por L. Malaguzzi en Reggio Emilia considero que aporta ideas y propuestas prácticas valiosas. $\mathrm{O}$ las reflexiones e investigaciones de la red internacional Another Roadmap for Arts Education (https://colivre.net/anotherroadmap), que reúne educadoras/es e investigadoras/es en museos, universidades, colegios y en proyectos culturales y educativos que entienden la mediación y educación artística como una práctica comprometida y crítica.

Carlos Escaño: Es cierto que hay países que mantienen actitudes más propiciatorias ante la educación artística como Francia, Finlandia o Nueva Zelanda, pero en términos generales, la educación artística sigue estando en el fondo de la escala académica. Aunque conviene tener en cuenta las investigaciones internacionales, me parece más oportuno buscar modelos innovadores en contextos cercanos o propios, puesto que cada coyuntura mantiene una idiosincrasia cultural específica. Tenemos bastante que aprender sobre la manera pedagógica globalizada que se trabaja en muchos centros de educación infantil en nuestro país. La educación infantil ha sido y es ahora más que nunca un espejo en el que mirarse para recuperar ideas fundamentales y depurar las cuestiones más esenciales de la educación. Observar la manera en la que las artes funcionan como eje transversal en la actividad pedagógica de muchas aulas de educación infantil, los modos en que se democratizan los tiempos y espacios, así como la preocupación por poner al niño y la niña como eje educativo real - insisto, antes y ahora - es algo sobre lo que tenemos que aprender desde la segmentación y fragmentación de otros niveles educativos. 


\section{Ricard Huerta: ¿Cómo deberíamos implicar a museos y otras instituciones en nuestras investigaciones y en nuestros avances metodológicos?}

Estitxu Aberasturi: A través de proyectos colaborativos de investigación, donde generemos conocimiento entendido como un bien que fomenta la innovación y mejora de la calidad, favoreciendo la visibilidad de las instituciones. Se trata de proponer a los museos e instituciones culturales investigaciones donde se busque invertir en innovación y desarrollo a medio o largo plazo. El desarrollo viene desde la investigación, no se trata de generar datos para beneficio universitario, se trata de una colaboración en la que se enriquecen ambas partes, generando otra economía más relacional y centrada en las personas.

Carmen María: Creo que los museos van en buena dirección, salen de las aulas y van a los centros con proyectos como Resistències artistiques, que une el mundo del arte con el de la educación llevando artistas a los centros educativos. O Dibuixar al So, en el que los museos nos abren las puertas a los centros educativos para un encuentro performativo de las artes, o el IVAM, que presta su apoyo a la AVPD (Associació Valenciana de Professorat de Dibuix), facilitando la organización de las Jornadas de Intercambio de Experiencias Didácticas del Área Plástica, Visual y Audiovisual, a la que han asistido profesionales como Mayalen Piqueras y Carlos Escaño. Los talleres didácticos están bien, pero hay que ir un paso más allá. Me gustaría crear grupos de trabajo con los museos, iniciar líneas de intervención más colaborativas, que se nos escuche más, que nos lance a la investigación con artistas, con instituciones. Este tipo de proyectos son los que nos hacen crecer como docentes, y esto revierte en nuestro alumnado.

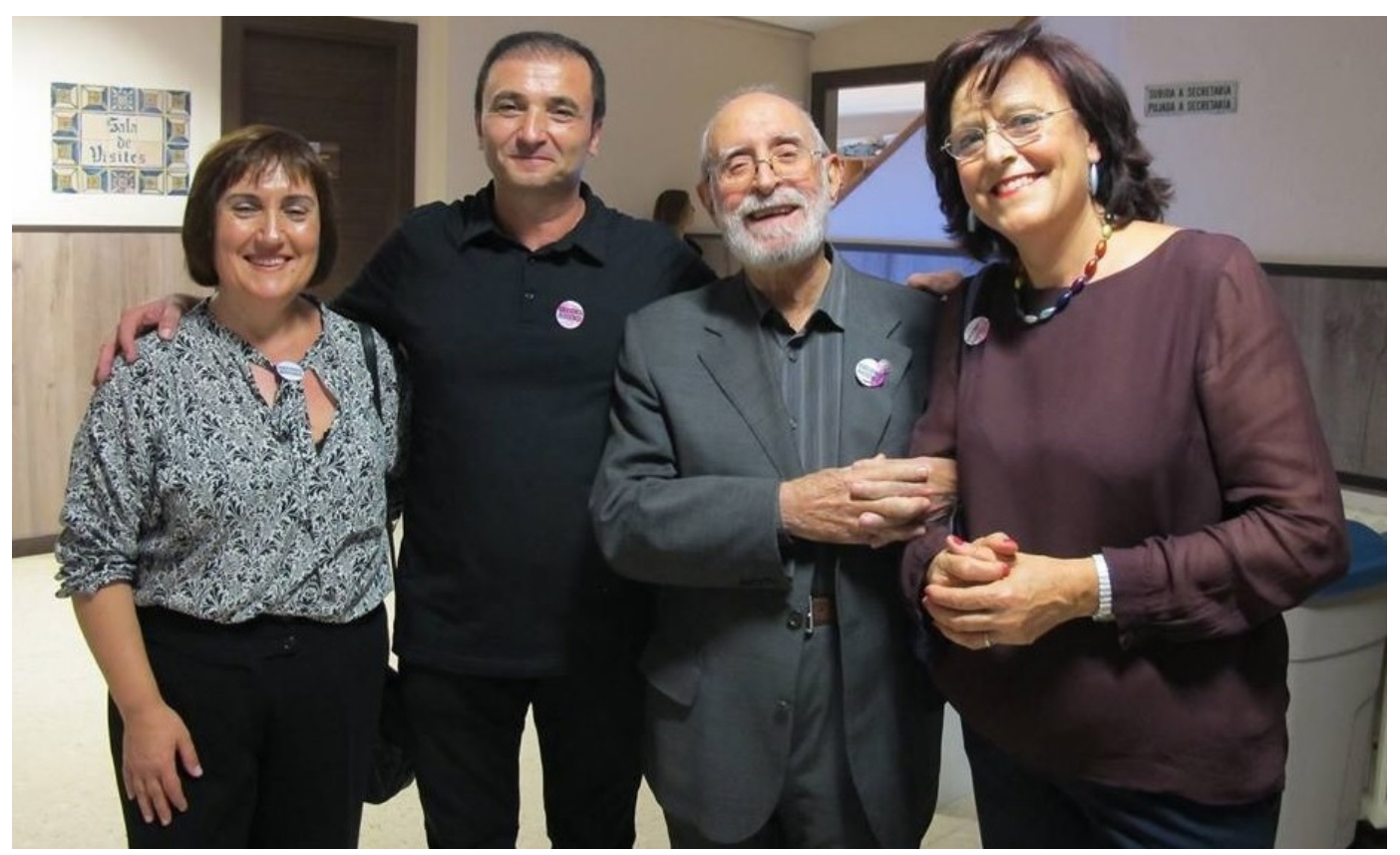

Figura 3. Carmen María Belmonte (a la izquierda) junto a Ricard Huerta, Romà de la Calle y Ana Sáenz. 
Carlos Escaño: El ámbito museológico no es mi campo de estudio. No me siento capacitado para dar una respuesta especializada en este terreno. Muy poco podría decir y tendría que ver con los aspectos vinculados a los modos comunicativos que se articulan en los centros de artes y museos, cuestión que es transversal en dinámicas educativas. Pero, si dentro del conjunto de instituciones al que te refieres podemos ubicar a las organizaciones no gubernamentales con finalidad social y aquellas directamente vinculadas al tercer sector, en ese caso sí mantengo intereses y experiencia que pueden servir como respuesta. La experiencia en contextos de cooperaciónal desarrollo, coninstituciones comprometidas con sus entornos, culturas, sociedades y causas, me ha mostrado claramente que la educación artística debe mantener siempre los pies en la tierra, que nuestras investigaciones y metodologías, sean de la naturaleza que sea, deben estar en aras de la transformación social.

\section{Ricard Huerta: ¿Existe un verdadero encuentro entre lo que ocurre en la universidad y en primaria y secundaria, en materia de educación artística?}

Carlos Escaño: La respuesta es clara: no. La universidad en términos generales ha vivido y vive de espaldas a lo que sucede en otros niveles educativos. Y creo que esto tiene una posible explicación en la falta de exigencia formativa - de manera preceptiva - en materia pedagógica que se nos solicita como profesorado en la universidad a la hora de ejercer la docencia. Es decir, al igual que al profesorado de educación infantil, educación primaria o secundaria se les exige estudios obligatorios en formación pedagógica (que pueden ser peores o mejores, pero existe una exigencia normativa y eso es un mensaje social muy claro), al profesorado de universidad no se nos exige formación docente preceptiva ninguna para poner un pie en un aula. Ha tenido que ser el voluntarismo del profesorado interesado el que palíe la situación que debiera de ser acometida de pleno por el Estado en términos normativos. No puede recaer exclusivamente sobre la voluntad y los hombros de los y las docentes el hecho de formarse pedagógicamente. Cada uno hemos buscado nuestras soluciones formativas a nuestra manera, y jamás se nos ha exigido una formación preceptiva en "pedagogía de..." para ejercer nuestra profesión. Esto pasa en todas las áreas, y en la nuestra también mantenemos ese problema, que se traduce en una desconexión inevitable del ámbito educativo.

Carmen María: en cuanto a educación artística se refiere, primaria y secundaria apenas tienen contacto, dado que no hay especialistas en primaria. En el paso a secundaria hay una brecha enorme, ahora mismo prácticamente insalvable. Con la universidad, ahora hay más contacto gracias al proyecto creado por Ricard Huerta Second Round, Art i Lluita als Instituts Valencians, en el que universidad e institutos de secundaria trabajamos codo a codo por la educación artística. Pero esto se debe a la voluntariedad de una persona y su equipo de trabajo. No está normalizado y es una excepción. Sería interesante. 


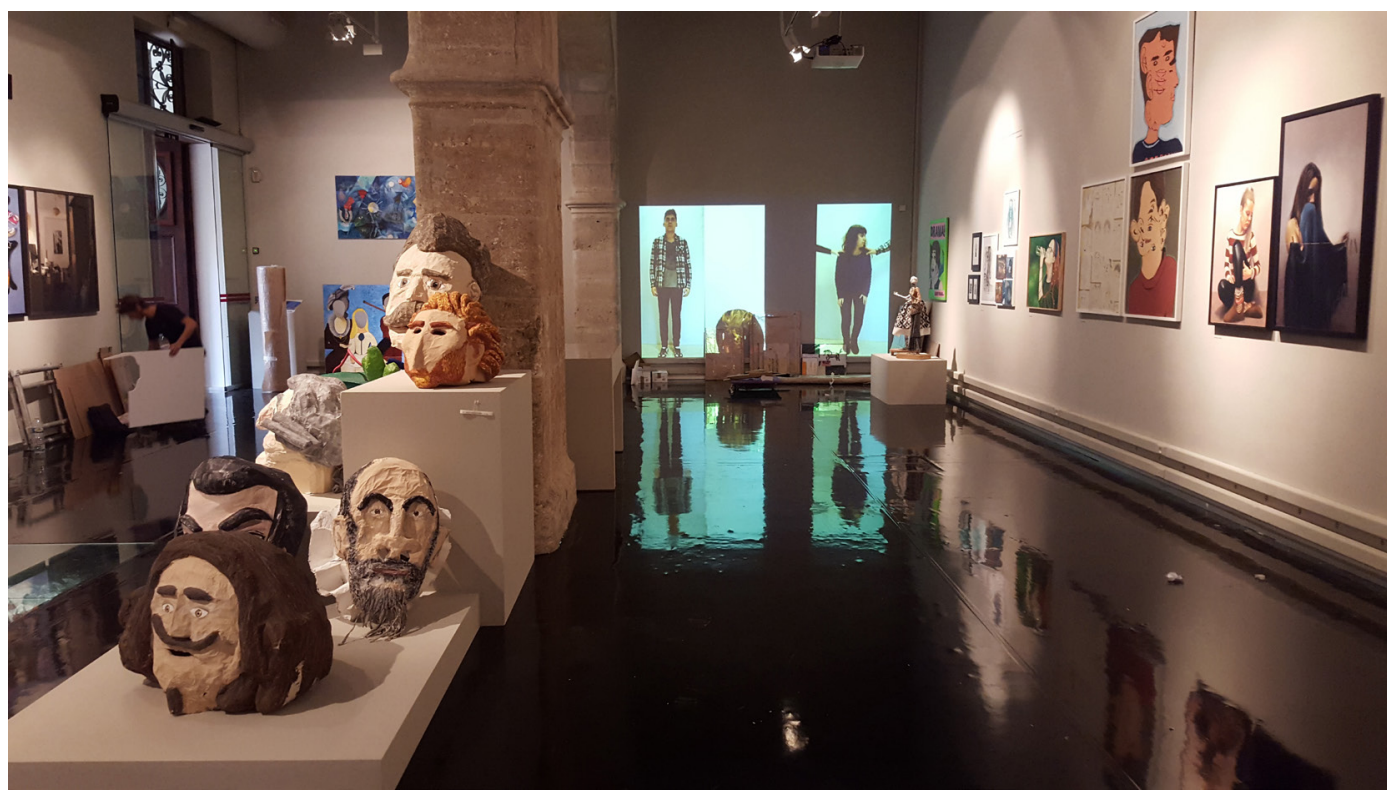

Figura 4. Exposición "Second Round" en el Centro Cultural La Nau de la Universitat de València. Al fondo se ve una instalación realizada por alumnado del IES Lluís Vives.

Estitxu Aberasturi: Considero que el encuentro todavía insuficiente, pero no podría ser de otra forma teniendo en cuenta que somos un área pequeña y con poca presencia en la formación. En mi Facultad de Educación, en el Grado de Educación Primaria, la asignatura del Arte y Cultura Visual supone el 4,7\% del total de las asignaturas, con una plantilla de cuatro profesores. ¿Cómo vamos a desarrollar un verdadero encuentro entre la universidad y escuela con este panorama? Eso sin mencionar la carrera incansable a la que está sometido el profesorado, con acreditaciones para poder alcanzar una estabilidad y dignidad laboral. A pesar de ello, contamos con una comunidad de práctica donde participamos una vez al mes docentes universitarios y de diferentes niveles educativos, donde aprendemos a partir de esta relación y desarrollamos proyectos que avanzan en un encuentro necesario y valioso entre universidad y escuela.

\section{Ricard Huerta: ¿Dada la situación actual, qué mensaje positivo podemos transmitir a las generaciones más jóvenes?}

Carmen María: Mensaje siempre positivo, pero luchando por dar una enseñanza de calidad. La educación artística es un pilar fundamental en la formación de niños y adolescentes, no la podemos abandonar, aunque los políticos lo hagan. Sabemos que es importante y hay que luchar. El arte nos hace más conscientes, al tener que enfrentarnos a diferentes soluciones. Esto es la creatividad, elegir entre múltiples posibilidades, tomar consciencia de que hay diversas opciones para comunicar y expresar. La educación artística forma ciudadanos capaces de leer e interpretar los mensajes que llegan a través de las imágenes, y a su vez de producirlos. Nuestra tarea consiste en dotar de herramientas y habilidades para ello. 
Carlos Escaño: Paulo Freire exponía que él era esperanzado por imperativo social e histórico. Las y los educadores siempre tenemos que abordar nuestra tarea con un sentido de esperanza. En nuestro caso no es una opción. Si no sabemos o no podemos, mejor que nos dediquemos a otra cosa. Si no somos capaces de lanzar un mensaje de cambio, mejor que busquemos otra profesión. Ser pesimista es una pose de la que se abusa en ciertos foros de supuesto progresismo, porque nos sitúa aparentemente en el campo de la crítica, pero curiosamente el pesimismo en la educación está hermanado a lo reaccionario y conservador: nos impide avanzar y transformar. Lanzar un mensaje de cambio y de esperanza no es ser ingenuo ni tampoco ausentarse del ejercicio crítico, sino todo lo contrario. Precisamente porque se es crítico y se analiza el cinismo del sistema y del contexto es más necesario abordar la transformación social.

Estitxu Aberasturi: Considero que la situación actual nos ha dado la oportunidad de pararnos, bajar el ritmo y pensar-sentir de forma más serena y tranquila lo que nos ocurre (personal y socialmente). Las generaciones más jóvenes, que relacionaban las tecnologías con su tiempo de ocio, han padecido el aislamiento, soledad y frustración, cuando han tratado de hacer un uso educativo a través de estos recursos. Esta situación y el regreso a una no normalidad, nos vuelve a colocar frente a la incertidumbre. El desconcierto y la imposibilidad de poder pensar a largo plazo, nos ha colocado por primera vez en el presente y no en el futuro. La buena noticia es que dicho presente se puede cambiar tomando como punto de partida las certezas actuales y asumiendo las incertezas futuras. Y en este cambio, la educación artística supone una oportunidad para educar a personas reflexivas, críticas, creativas y responsables, comprometidas socialmente, para afrontar muchos de los retos del siglo XXI. Podemos imaginar un nuevo escenario educativo atravesado por las artes, donde aprender tenga sentido.

\section{Ricard Huerta: ¿Hay algo más que os gustaría destacar?}

Estitxu Aberasturi: Calma, serenidad y escucha. La respuesta no está en el método, sino en el discurso y el posicionamiento. Comienza por hacerte preguntas: ¿Qué entiendo que es aprender?, ¿Cómo aprendo a través de las artes?, ¿Cuándo podría introducir algún cambio?, ¿Por qué hacerlo a través de las artes?, ¿Sobre qué referentes he pensado hacerlo?, etc.

Carmen María: Desearía que cada vez más docentes de artes se uniesen para tener fuerza como especialistas y para tener voto ante los políticos que nos ningunean, sean del signo que sean. El asociacionismo corporativo es muy importante, y animo al profesorado de dibujo a asociarse a nivel de comunidades $\mathrm{y}$, por supuesto, a federarse en la Federación Nacional de Profesorado de Dibujo. Nadie va a hacer el trabajo por nosotros, y nosotros lo hemos de hacer por nuestro alumnado. ¿Si nosotros no le damos la importancia que tiene la educación artística, quien lo va a hacer? 
Carlos Escaño: Agradeceros la oportunidad de dialogar con vosotros sobre esta situación y sus diferentes derivaciones. Es un placer participar en espacios para la reflexión tan necesarios como este. 